\title{
Type and location of flexor hallucis longus musculotendinous junctions and its tendinous interconnections with flexor digitorum longus tendon: pertinent data for tendon harvesting and transfer
}

\author{
P. Wan-ae-loh'1, T. Huanmanop², S. Agthong ${ }^{2}$, V. Chentanez ${ }^{2}$ \\ ${ }^{1}$ Medical Science Programme, Faculty of Medicine, King Chulalongkorn Memorial Hospital, \\ Chulalongkorn University, Bangkok, Thailand \\ 2Department of Anatomy, Faculty of Medicine, King Chulalongkorn Memorial Hospital, \\ Chulalongkorn University, Bangkok, Thailand
}

[Received: 16 April 2021; Accepted: 29 June 2021; Early publication date: 21 July 2021]

Background: Anatomy of flexor hallucis longus (FHL) is essential for the achievement of tendon transfer and several procedures performed in the foot and ankle. The aim of this study was to evaluate the anatomical knowledge of FHL including the type and location of musculotendinous junction (MTJ), tendinous interconnections (TIC) morphology, its location related to Master Knot of Henry (MKH), and the pattern of TIC distribution.

Materials and methods: One hundred and sixty-six legs from 52 embalmed and 31 soft cadavers were assessed. The medial (MB) and lateral (LB) bellies of FHL were identified and traced until the end of the most distal muscle fibre to determine the medial and lateral MTJS. MTJ was classified into four types based on the existence and length of $M B$ and $L B$ : type 1, long $L B$ and shorter $M B$; type 2, equal length of both bellies; type 3, only $L B$ and no $M B$; type 4, long $M B$ and shorter LB. Low lying muscle belly was defined as muscle extending beyond the zero point (the point of intersection between distal osseous part of tibia and FHL tendon). The distance between MTJ and zero point was measured. TIC was classified into seven types based on the direction and number of slip: type I, one slip from FHL to flexor digitorum longus (FDL); type II, crossed connection: type III, one slip from FDL to FHL; type IV, no connection; type $V$, two slip from FHL to FDL; type VI, two slip from FHL to FDL and one slip from FDL to FHL; type VII, two slips from FDL to FHL and one slip from FHL to FDL. The distance between the TIC and MKH was measured. TIC distribution was defined into four types based on slip distribution to lesser toes: type a, distributed to second toe; type $b$, distributed to second and third toes; type c, distributed to second to fourth toes, and type $d$, distributed to second to fifth toes.

Results: Type 1 and type 3 of MTJ morphology were found in $87.3 \%$ and $12.7 \%$, respectively. Low lying $L B$ was detected in $66.13 \%$ of cases with a mean distance of $13.10 \pm 4.51 \mathrm{~mm}$. All MBs ended proximal to the zero point with a mean

Address for correspondence: V. Chentanez, MD, PhD, Department of Anatomy, Faculty of Medicine, King Chulalongkorn Memorial Hospital, Chulalongkorn University, Bangkok 10330, Thailand, tel: 66-860701084, e-mail: fmedvct@gmail.com

This article is available in open access under Creative Common Attribution-Non-Commercial-No Derivatives 4.0 International (CC BY-NC-ND 4.0) license, allowing to download articles and share them with others as long as they credit the authors and the publisher, but without permission to change them in any way or use them commercially. 
distance of $-21.99 \pm 13.21 \mathrm{~mm}$. Three types of TIC $(I, I I, V)$ were identified. The highest frequency was type I (82.93\%). In addition, a new type of TIC was depicted in $8.53 \%$ of cases. Part of the FHL tendon in this type fused with FDL tendon and the rest extended directly to the first toe. TIC could be located either proximal, distal or at the MKH. The highest prevalence was distal to MKH in $51.67 \%$ of cases with a mean distance of $11.23 \pm 5.13 \mathrm{~mm}$ and $8.73 \pm 4.2 \mathrm{~mm}$ in low lying and non-low-lying groups, respectively. Four types of slip distribution to lesser toes were defined, mostly in type b. No statistically significant differences were detected among all parameters including genders, sides, and groups.

Conclusions: Knowledge of this investigation might enhance the clinical efficacy of tendon harvesting and transfer in foot and ankle surgery. (Folia Morphol 2022; 81, 3: 766-776)

Key words: flexor hallucis longus, flexor digitorum longus, musculotendinous junction, tendinous interconnection

\section{INTRODUCTION}

Flexor hallucis longus (FHL) transfer is a widely used technique for ankle and foot reconstruction, including posterior tibial insufficiency, Achilles tendinopathies, or peroneal tendon rupture $[2,4,6,13$, $21,22,24]$. The FHL is suitable for transfer because of its strength, axis and amplitude of contraction, and coincident action with gastrocnemius and soleus muscles [33]. The objectives of FHL transfer are to repair the length, strengthen the injured tendon, and corporate more muscle force [8]. Moreover, FHL transfer can decrease pain by normalising vascularity $[1,8]$. Many techniques of FHL tendon graft harvesting are clinically utilised, including single incision, double incision, and minimally invasive techniques [16]. The indication, length of harvested tendon and location of incisions are different among techniques [16]. FHL tendons can be harvested behind the medial malleolus, proximal to superior border of the calcaneus, along medial edge of mid-foot at Master Knot of Henry (MKH), or over the medial plantar aspect of forefoot at the first metatarsophalangeal joint [2, 21, 28]. Despite the good to excellent clinical outcome following FHL transfer that was revealed previously, complications such as neurovascular injury, cock-up deformity, and functional loss of toes were also reported $[1,10,16,20]$.

Knowing the anatomical variation of the $\mathrm{FHL}$ muscle is helpful when planning an operation. If FHL muscle bellies are sufficient to cover the tendon defect, the other combining techniques are not necessary $[17,24]$. Tendon transfer can improve blood supply in the injured region and covers possible ex- isting soft tissue defects. To accomplish the clinical objective, knowledge of the anatomical variations of musculotendinous junction (MTJ) of FHL will provide important insights to decide upon the operation and administration of FHL transfer [17, 24].

Tendinous interconnections (TIC) between FHL and flexor digitorum longus (FDL) play an important role in tendon harvesting [25]. The benefit of these connections is to act as a natural tenodesis during harvesting tendon grafts proximal to $\mathrm{MKH}$ and to increase the length of tendon graft by cutting the connections [15, 23]. The connections between FHL and FDL, which have an important functional role in toe movements, might restrict harvesting of the FHL tendon proximal to MKH [10]. Previous research has suggested that, these interconnections must be cut when harvesting FHL tendon especially in minimal invasive technique $[16,25]$. To reduce the risk of iatrogenic injury during surgical procedures and achieve medical procedures, essential knowledge of morphological type, location and distribution of TIC are necessary $[26,30]$. The focus in this cadaveric study was to evaluate the anatomical knowledge of FHL including the type and location of MTJ, TIC morphology and its location related to $\mathrm{MKH}$, and the pattern of TIC distribution.

\section{MATERIALS AND METHODS}

This study was performed in 166 legs from 52 embalmed (33 males, 19 females) and 31 soft cadavers ( 9 males and 22 females) supported by the Department of Anatomy and Chula Soft Cadaver Surgical Training Centre, Faculty of Medicine, Chulalongkorn 


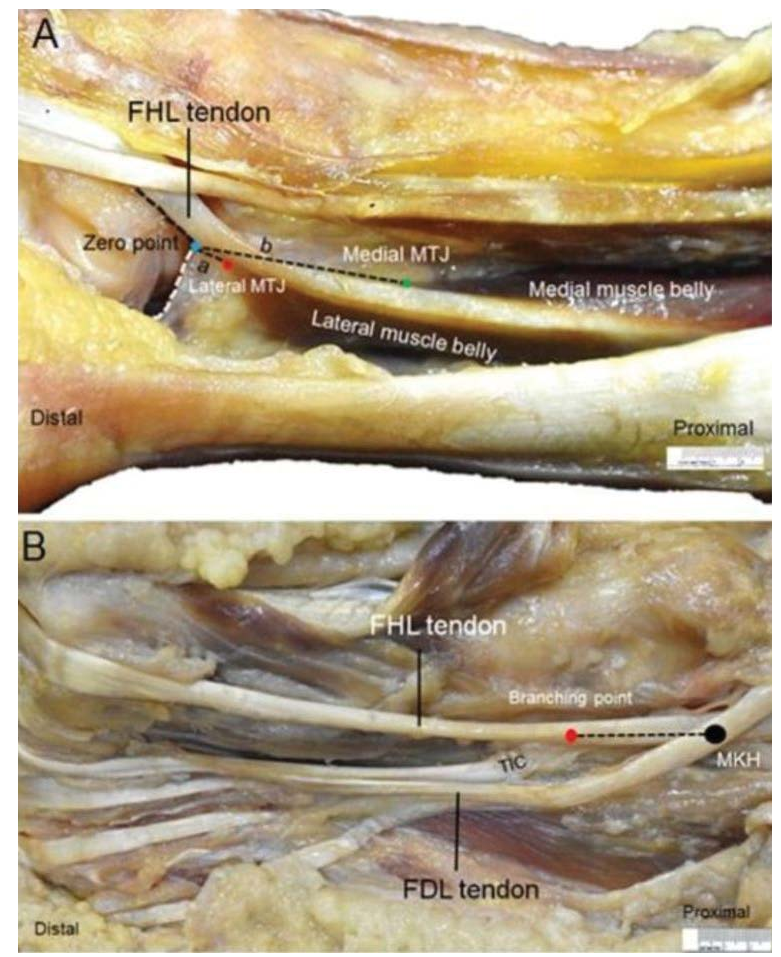

Figure 1. A. Photograph of left ankle showing; (a) distance from lateral musculotendinous junction (MTJ) (red dot) and (b) distance from medial MTJ (green dot) of flexor hallucis longus muscle (FHL) to zero point (blue dot) which is the intersection between distal osseous part of tibia (white dot line) and FHL tendon (black dot line); B. Photograph of right plantar surface of foot showing the distance from branching point of tendinous interconnection (TIC) (red dot) to master knot of Henry (MKH) (black dot); FDL — flexor digitorum longus muscle.

University. The mean age of the cadavers was $78.87 \pm$ \pm 13.69 years (range 32-100). None of the cadaveric legs, ankles and feet had damage, deformity, or scaring from previous surgery.

\section{Cadaveric dissection}

The skin, subcutaneous tissue, fascia of the leg, and plantar surface of the foot was detached to each side. At the medial side of the ankle, the flexor retinaculum was identified, and its posterior edge was cut to open the tarsal tunnel. The dissection was performed until adequate exposure of the FHL tendon was achieved. The medial and lateral bellies of FHL were identified and traced until the end of the most distal muscle fibre to determine the medial and lateral MTJs (Fig. 1A). Then, the plantar aponeurosis and medial plantar fascia of the foot were cut to expose the flexor digitorum brevis (FDB) and abductor hallucis muscle $(A H)$. These two muscles were separated to disclose the tendon of FHL and FDL. MKH was indicated at the crossing point of FDL and FHL tendon
(Fig. 1B). The TIC was also explored. Finally, FHL and FDL together with TIC and quadratus plantae were harvested as one block from the cadaver to analyse the type of MTJ and TIC.

\section{Observations and measurements \\ Type of MTJ, MTJ location and the presence of low lying $F H L$}

The presence of medial (MB) and lateral (LB) bellies of FHL muscle was observed in both embalmed and soft cadavers. MTJ morphological types were classified according to the criteria established by Pichler et al. [24] and modified by Mao et al. [17] into four types: type 1, long $L B$ and shorter MB; type 2, equal length of both bellies; type 3 , only LB and no $M B$; type 4, long MB and shorter LB. The presence of other morphologies was also examined. However, the MTJ location and the presence of low lying FHL were examined only in soft cadavers since the foot and ankle joint should be set in a neutral position throughout these processes. The zero point was defined according to Pichler et al. [24] as the point of intersection between the distal osseous part of the tibia and FHL tendon (Fig. 1A) and the presence of low lying FHL was depicted if the muscle belly extended distal to the zero point. Distances from medial and lateral MTJs to the zero point were measured with a digital slide gauge (Mitutoyo ${ }^{\circledR}$ 0-150 mm; range $150 \mathrm{~mm}$, resolution $0.01 \mathrm{~mm}$ ) (Fig. 1A). This parameter was recorded as either a negative or positive value based on whether it located proximal or distal to the zero point, respectively.

\section{Type of TIC, its distribution to the toes and its location regarding $\mathrm{MKH}$}

The presence and direction of TIC between FHL and FDL were examined in both embalmed and soft cadavers. Type of TIC was classified based on the criteria defined by Beger et al. [3] into seven types: type I, one slip from FHL to FDL; type II, crossed connection: type III, one slip from FDL to FHL; type IV, no connection; type V, two slip from FHL to FDL; type VI, two slip from FHL to FDL and one slip from FDL to FHL; type VII, two slips from FDL to FHL and one slip from FHL to FDL. The presence of other patterns was also examined. The distribution of TIC to the lesser toes was identified by pulling the $\mathrm{FHL}$ and observing the flexion of the toes. TIC distribution was defined into four types according to Plaass et al. [25] as the following: type $a$, distributed to second toe; type $b$, 
distributed to second and third toes; type $c$, distributed to second to fourth toes and type d, distributed to second to fifth toes. Moreover, the distance from the branching point of TIC to MKH was measured to determine the location of TIC in 60 soft cadaver specimens (Fig. 1B). This parameter was recorded as negative or positive value based on whether it located proximal or distal to the MKH, respectively.

Each parameter was measured twice by the same investigator. The same digital Vernier calliper was used to ensure consistency.

\section{Statistical analysis}

Statistical analysis was performed by SPSS software version 22.0. Morphology of MTJ, TIC and the distribution of TIC were analysed as prevalence and percentage. All quantitative data was based on the criteria reported as range, mean and standard deviation. Unpaired t-test (for parametric test) and Mann-Whitney $U$ test (for nonparametric test) were used to compare between genders and between low lying and non-low lying groups. The difference between left and right side was examined with paired t-test (for parametric test) or Wilcoxon signed-rank test (for nonparametric test). A p-value of less than 0.05 was defined as statistically significant.

\section{Ethical consideration}

The Institutional Review Board (IRB) of the Faculty of Medicine, Chulalongkorn University approved this anatomical study (IRB NO. 636/62).

\section{RESULTS}

Type of MTJ, MTJ location and the presence of low lying FHL

Musculotendinous junction morphology was examined in 166 specimens from both soft and embalmed cadavers. Two morphological types of MTJ were identified including type 1 (145 cases, 87.35\%), in which the $L B$ ended more distally than $M B$, and type 3 (21 cases, 12.65\%), which showed only LB (Fig. 2, Table 1). Symmetrical type of MTJ morphology was found in 74 cadavers ( $89.16 \%$ of cases) and the highest frequency was type 1. However, FHL which had equal length of $M B$ and $L B$ or type 2 and those with $\mathrm{MB}$ ended more distally than $\mathrm{LB}$ or type 4 were not found in this study.

Musculotendinous junction location was determined in 62 legs of soft cadavers by measuring the distance from medial and lateral MTJs to the zero
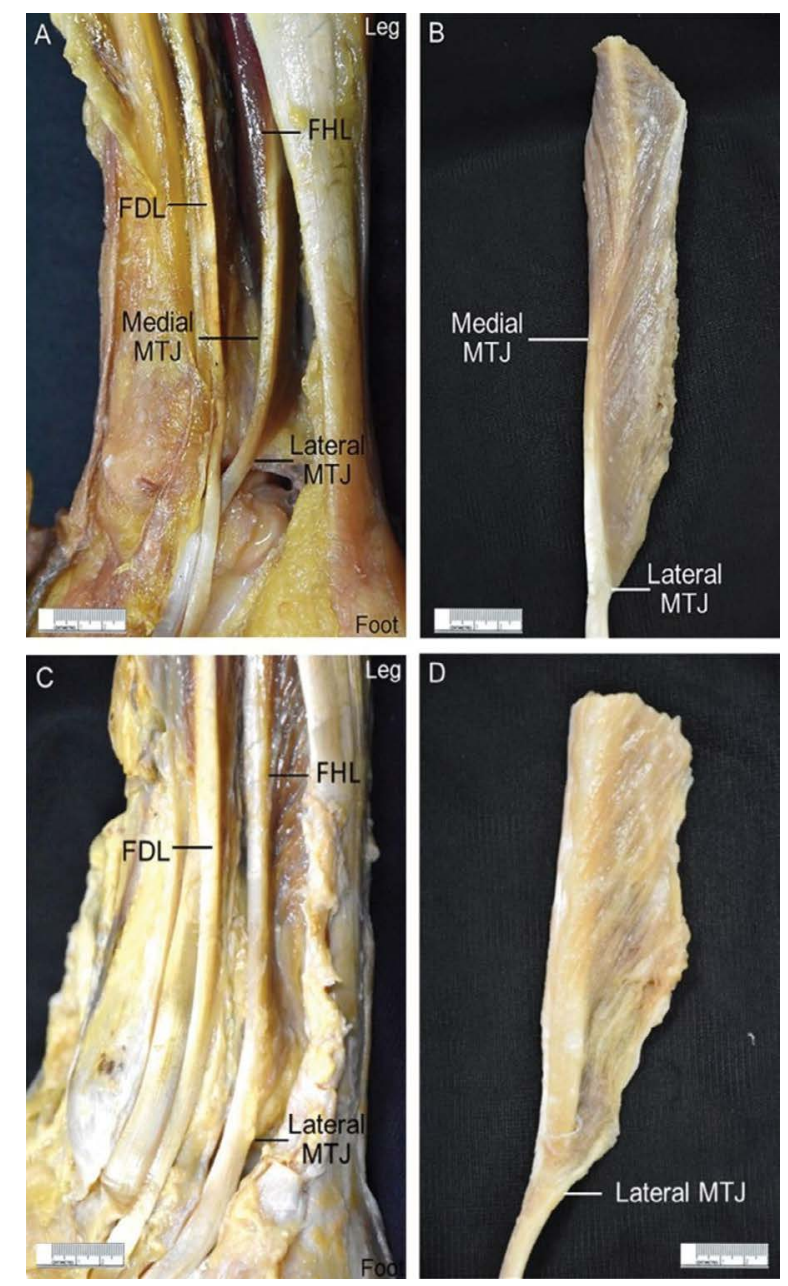

Figure 2. Photographs of medial side of right legs and resected flexor hallucis longus muscle (FHL) musculotendinous junction (MTJ) showing type 1 MTJ morphology with a longer lateral muscle belly than medial muscle belly (A, B), and type 3 MTJ morphology with only a lateral muscle belly (C, D); FDL — flexor digitorum longus.

point. Results are shown in Table 2. MTJ was found to reside either proximal (-) or distal (+) to zero point. LB extended beyond the zero point (low-lying) in $41(66.13 \%)$ cases with a mean distance of $13.10 \pm$ $\pm 4.51 \mathrm{~mm}$. In the non-low-lying group of LB (21 cases, $33.87 \%$ ), the mean distance from the zero point was $-8.5 \pm 7.30 \mathrm{~mm}$. In contrast, all MB ended proximally to the zero point with a mean distance of $-21.99 \pm 13.21 \mathrm{~mm}$. No statistically significant difference was found between genders, sides, and groups.

Type of TIC, its distribution to the toes and its location regarding $\mathrm{MKH}$

Type of TIC was examined in 164 specimens (2 damaged specimens from dissection were excluded). According to Beger et al. [3], types I, II, V and 
Table 1. Prevalence of musculotendinous junction (MTJ) morphology, low lying of flexor hallucis longus (FHL), tendinous interconnection (TIC) morphology and TIC distribution

\begin{tabular}{|c|c|c|c|c|c|c|c|}
\hline & \multicolumn{3}{|c|}{ Male } & \multicolumn{3}{|c|}{ Female } & \multirow[t]{2}{*}{ Total } \\
\hline & Left & Right & Total & Left & Right & Total & \\
\hline \multicolumn{8}{|c|}{ Type of MTJ morphology (166 specimens) } \\
\hline 1 & $35(21.08 \%)$ & $32(19.28 \%)$ & $67(40.36 \%)$ & $39(23.49 \%)$ & $39(23.49 \%)$ & $78(46.99 \%)$ & $145(87.35 \%)$ \\
\hline 3 & $7(4.22 \%)$ & $10(6.02 \%)$ & $17(10.24 \%)$ & $2(1.20 \%)$ & $2(1.20 \%)$ & $4(2.41 \%)$ & $21(12.65 \%)$ \\
\hline \multicolumn{8}{|c|}{ Low lying of FHL (62 soft cadaveric specimens) } \\
\hline Lateral muscle belly & $7(11.29 \%)$ & $7(11.29 \%)$ & $14(22.58 \%)$ & $13(20.97 \%)$ & $14(22.58 \%)$ & $27(43.55 \%)$ & $41(66.13 \%)$ \\
\hline Medial muscle belly & $0(0 \%)$ & $0(0 \%)$ & $0(0 \%)$ & $0(0 \%)$ & $0(0 \%)$ & $0(0 \%)$ & $0(0 \%)$ \\
\hline Non low lying & $2(3.23 \%)$ & $2(3.23 \%)$ & $4(6.45 \%)$ & $9(14.52 \%)$ & $8(12.90 \%)$ & $17(27.42 \%)$ & $21(33.87 \%)$ \\
\hline \multicolumn{8}{|c|}{ Type of TIC (164 specimens) } \\
\hline I & $34(20.73 \%)$ & $34(20.73 \%)$ & $68(41.46 \%)$ & $33(20.12 \%)$ & $35(21.34 \%)$ & $68(41.46 \%)$ & $136(82.93 \%)$ \\
\hline$\|$ & $1(0.61 \%)$ & $0(0 \%)$ & $1(0.61 \%)$ & $0(0 \%)$ & $0(0 \%)$ & $0(0 \%)$ & $1(0.61 \%)$ \\
\hline V & $4(2.44 \%)$ & $4(2.44 \%)$ & $8(4.88 \%)$ & $3(1.83 \%)$ & $2(1.22 \%)$ & $5(3.05 \%)$ & $13(7.93 \%)$ \\
\hline New type & $2(1.22 \%)$ & $3(1.83 \%)$ & $5(3.05 \%)$ & $5(3.05 \%)$ & $4(2.44 \%)$ & $9(5.49 \%)$ & $14(8.53 \%)$ \\
\hline \multicolumn{8}{|c|}{ Type of TIC distribution (164 specimens) } \\
\hline a & $11(6.71 \%)$ & $7(4.27 \%)$ & $18(10.98 \%)$ & $6(3.66 \%)$ & $8(4.88 \%)$ & $14(8.54 \%)$ & $32(19.51 \%)$ \\
\hline b & $25(15.24 \%)$ & $28(17.07 \%)$ & $53(32.31 \%)$ & $32(19.51 \%)$ & $26(15.85 \%)$ & $58(35.36 \%)$ & $111(67.68 \%)$ \\
\hline c & $5(3.05 \%)$ & $6(3.66 \%)$ & $11(6.71 \%)$ & $1(0.61 \%)$ & $6(3.66 \%)$ & $7(4.27 \%)$ & $18(10.98 \%)$ \\
\hline$d$ & $0(0 \%)$ & $0(0 \%)$ & $0(0 \%)$ & $2(1.22 \%)$ & $1(0.61 \%)$ & $3(1.83 \%)$ & $3(1.83 \%)$ \\
\hline
\end{tabular}

a new type were found (Table 1, Fig. 3). The highest frequency was type I (82.93\%), which had a tendinous slip branching from FHL to FDL tendon followed numerically by type $\mathrm{V}$ (7.93\%), which had double slip from FHL to FDL tendons and type II (0.61\%), which showed the cross tendinous slips between $\mathrm{FHL}$ and FDL tendons, respectively. In addition, a new type of interconnection (14 cases or $8.54 \%$ ) was found in which part of the FHL tendon fused with FDL tendon and the rest extended directly to the first toe (Fig. 3G, H). Symmetrical type of TIC was found in 61 cadavers $(79.27 \%$ of cases) and the highest frequency was type 1.

Distribution of TIC to the lesser toes was determined by observing the movement of each toe when pulling the FHL. Prevalence of each type is shown in Table 1. The most common was type b (67.68\%) and followed numerically by type a, type c and type $d$, respectively. Symmetrical type of slip distribution to lesser toes was found in 61 cadavers $(74.39 \%)$ and the highest frequency was type $b$. The prevalence of TIC distribution in the new type of this study was type a (1 case), type b (10 cases) and type c (3 cases).

The location of TIC was investigated in $60 \mathrm{soft}$ cadaver specimens of. It was located either proximal (-), distal (+) to MKH or at the MKH (Table 2). The highest prevalence was located distally to $\mathrm{MKH}$ in $36.67 \%$ with a mean distance of $11.23 \pm 5.13 \mathrm{~mm}$ in the low-lying group and $15 \%$ in the non-low-lying group with a mean distance of $8.73 \pm 4.2 \mathrm{~mm}$. In the new type of TIC, the fusion point in the soft cadaveric specimens was located either proximal ( 4 cases), distal (5 cases) or at the MKH ( 2 cases). No statistically significant difference was found between genders, sides, and groups.

\section{DISCUSSION}

Achilles tendon ruptures occur approximately at 2-6 cm above the calcaneal insertion and the blood supply in this region might be reduced [24]. FHL tendon transfer can cover the soft tissue defect and improve blood supply. The location of the MTJ is important in this instance. If MTJ is located proximally, the FHL muscle bellies are insufficient for the coverage of injured tendon and adequate vascular supply to the affected area. Therefore, knowledge of morphological variation of FHL muscle in this study will provide some benefits in tendon harvesting and transfer. In this study, only type 1 and 3 of MTJ morphology were found with the most frequent type as type 1 (LB longer than MB). Moreover, symmetrical type of MTJ morphology was found with high prevalence $(89.16 \%$ 
Table 2. Mean distances from medial and lateral musculotendinous junction (MTJ) to zero point and from tendinous interconnection (TIC) to Master Knot of Henry (MKH)

\begin{tabular}{|c|c|c|c|c|c|c|c|}
\hline & \multicolumn{3}{|c|}{ Male } & \multicolumn{3}{|c|}{ Female } & \multirow[t]{2}{*}{ Total } \\
\hline & Left & Right & Total & Left & Right & Total & \\
\hline \multicolumn{8}{|c|}{ Mean distance from MTJ to zero point [mm] (62 soft cadaveric specimens) } \\
\hline Lateral belly & $\begin{array}{c}9 \\
8.59 \pm 9.60 \\
(-6.54-20.88)\end{array}$ & $\begin{array}{c}9 \\
8.95 \pm 10.24 \\
(-8.39-21.21)\end{array}$ & $\begin{array}{c}18 \\
8.77 \pm 9.63 \\
(-8.39-21.21)\end{array}$ & $\begin{array}{c}22 \\
3.86 \pm 11.77 \\
(-18.27-20.96)\end{array}$ & $\begin{array}{c}22 \\
5.40 \pm 12.97 \\
(-30.62-5.54)\end{array}$ & $\begin{array}{c}44 \\
4.63 \pm 12.26 \\
(-30.62-20.96)\end{array}$ & $\begin{array}{c}62(100 \%) \\
5.83 \pm 11.64 \\
(-30.62-21.21)\end{array}$ \\
\hline Low lying & $\begin{array}{c}7 \\
12.73 \pm 5.75 \\
(5.85-20.88)\end{array}$ & $\begin{array}{c}7 \\
13.33 \pm 6.15 \\
(5.91-21.21)\end{array}$ & $\begin{array}{c}14 \\
13.03 \pm 5.73 \\
(5.85-21.21)\end{array}$ & $\begin{array}{c}13 \\
12.46 \pm 4.03 \\
(5.76-20.96)\end{array}$ & $\begin{array}{c}14 \\
13.76 \pm 3.71 \\
(8.20-18.32)\end{array}$ & $\begin{array}{c}27 \\
13.13 \pm 3.85 \\
(5.76-20.96)\end{array}$ & $\begin{array}{c}41(66.13 \%) \\
13.10 \pm 4.51 \\
(5.76-21.21)\end{array}$ \\
\hline Non low-lying & $\begin{array}{c}2 \\
-5.88 \pm 0.93 \\
(-6.54--5.22)\end{array}$ & $\begin{array}{c}2 \\
-6.37 \pm 2.86 \\
(-8.39--4.35)\end{array}$ & $\begin{array}{c}4 \\
-6.13 \pm 1.76 \\
(-8.39--4.35)\end{array}$ & $\begin{array}{c}9 \\
-8.56 \pm 6.77 \\
(-18.27-0.00)\end{array}$ & $\begin{array}{c}8 \\
-9.23 \pm 9.73 \\
(-30.62-0.00)\end{array}$ & $\begin{array}{c}17 \\
-8.87 \pm 8.03 \\
(-30.62-0.00)\end{array}$ & $\begin{array}{c}21(33.87 \%) \\
-8.35 \pm 7.30 \\
(-30.62-0.00)\end{array}$ \\
\hline Medial belly & $\begin{array}{c}9 \\
-27.19 \pm 11.32 \\
(-42.12--12.78)\end{array}$ & $\begin{array}{c}9 \\
-21.57 \pm 6.46 \\
(-28.13--12.08)\end{array}$ & $\begin{array}{c}18 \\
-24.79 \pm 9.66 \\
(-42.12--12.78)\end{array}$ & $\begin{array}{c}22 \\
-22.34 \pm 13.84 \\
(-51.02--4.93)\end{array}$ & $\begin{array}{c}22 \\
-19.76 \pm 14.70 \\
(-65.95--5.54)\end{array}$ & $\begin{array}{c}44 \\
-21.08 \pm 14.16 \\
(-65.95--4.93)\end{array}$ & $\begin{array}{c}62 \\
-21.99 \pm 13.21 \\
(-65.95--4.93)\end{array}$ \\
\hline \multicolumn{8}{|c|}{ Mean distance from TIC to MKH [mm] (60 soft cadaveric specimens) } \\
\hline Low lying & $\begin{array}{c}6 \\
3.68 \pm 7.49 \\
(-9.04-12.34)\end{array}$ & $\begin{array}{c}6 \\
4.33 \pm 13.95 \\
(-20.81-17.56)\end{array}$ & $\begin{array}{c}12 \\
4.01 \pm 10.68 \\
(-20.81-17.56)\end{array}$ & $\begin{array}{c}13 \\
5.65 \pm 11.62 \\
(-21.33-18.06)\end{array}$ & $\begin{array}{c}14 \\
0.98 \pm 10.64 \\
(-15.75-20.52)\end{array}$ & $\begin{array}{c}27 \\
3.23 \pm 11.16 \\
(-21.33-20.52)\end{array}$ & $\begin{array}{c}39(65 \%) \\
3.47 \pm 10.88 \\
(-21.33-20.52)\end{array}$ \\
\hline Proximal & $\begin{array}{c}1 \\
-9.04\end{array}$ & $\begin{array}{c}1 \\
-20.81\end{array}$ & $\begin{array}{c}2 \\
-14.93 \pm 8.33 \\
(-20.81--9.04)\end{array}$ & $\begin{array}{c}2 \\
-15.94 \pm 7.66 \\
(-21.33--10.55)\end{array}$ & $\begin{array}{c}5 \\
-10.00 \pm 3.91 \\
(-15.75--6.13)\end{array}$ & $\begin{array}{c}7 \\
-11.70 \pm 5.31 \\
(-21.33--6.13)\end{array}$ & $\begin{array}{c}9(15 \%) \\
-12.42 \pm 5.65 \\
(-21.33--6.13)\end{array}$ \\
\hline At MKH & $\begin{array}{c}1 \\
0.00\end{array}$ & $\begin{array}{c}1 \\
0.00\end{array}$ & $\begin{array}{c}2 \\
0.00\end{array}$ & $\begin{array}{c}3 \\
0.00\end{array}$ & $\begin{array}{c}3 \\
0.00\end{array}$ & $\begin{array}{c}6 \\
0.00\end{array}$ & $\begin{array}{c}8(13.33 \%) \\
0.00\end{array}$ \\
\hline Distal & $\begin{array}{c}4 \\
7.78 \pm 3.58 \\
(4.58-12.34)\end{array}$ & $\begin{array}{c}4 \\
11.70 \pm 5.90 \\
(4.14-17.56)\end{array}$ & $\begin{array}{c}8 \\
9.74 \pm 4.98 \\
(4.14-17.56)\end{array}$ & $\begin{array}{c}8 \\
13.16 \pm 3.44 \\
(7.96-18.06)\end{array}$ & $\begin{array}{c}6 \\
10.63 \pm 7.01 \\
(5.04-20.52)\end{array}$ & $\begin{array}{c}14 \\
12.08 \pm 5.19 \\
(5.04-20.52)\end{array}$ & $\begin{array}{c}22(36.67 \%) \\
11.23 \pm 5.13 \\
(4.14-20.52)\end{array}$ \\
\hline Non-low-lying & $\begin{array}{c}2 \\
9.69 \pm 0.98 \\
(9.00-10.38)\end{array}$ & $\begin{array}{c}2 \\
0.00 \\
(0.00)\end{array}$ & $\begin{array}{c}4 \\
4.84 \pm 5.62 \\
(0.00-10.38)\end{array}$ & $\begin{array}{c}9 \\
0.08 \pm 7.08 \\
(-8.74-13.52)\end{array}$ & $\begin{array}{c}8 \\
1.83 \pm 9.10 \\
(-10.41-15.14)\end{array}$ & $\begin{array}{c}17 \\
0.90 \pm 7.88 \\
(-10.41-15.14)\end{array}$ & $\begin{array}{c}21(35 \%) \\
1.65 \pm 7.55 \\
(-10.41-15.14)\end{array}$ \\
\hline Proximal & 0 & 0 & 0 & $\begin{array}{c}4 \\
-5.88 \pm 2.77 \\
(-8.74--3.05)\end{array}$ & $\begin{array}{c}2 \\
-10.18 \pm 0.32 \\
(-10.41--9.96)\end{array}$ & $\begin{array}{c}6 \\
-7.31 \pm 3.10 \\
(-10.41--3.05)\end{array}$ & $\begin{array}{c}6(10 \%) \\
-7.31 \pm 3.10 \\
(-10.41--3.05)\end{array}$ \\
\hline At MKH & 0 & $\begin{array}{c}2 \\
0.00\end{array}$ & $\begin{array}{c}2 \\
0.00\end{array}$ & $\begin{array}{c}2 \\
0.00\end{array}$ & $\begin{array}{c}2 \\
0.00\end{array}$ & $\begin{array}{c}4 \\
0.00\end{array}$ & $\begin{array}{c}6(10 \%) \\
0.00\end{array}$ \\
\hline Distal & $\begin{array}{c}2 \\
9.69 \pm 0.98 \\
(9.00-10.38)\end{array}$ & 0 & $\begin{array}{c}2 \\
9.69 \pm 0.98 \\
(9.00-10.38)\end{array}$ & $\begin{array}{c}3 \\
8.07 \pm 4.72 \\
(5.22-13.52)\end{array}$ & $\begin{array}{c}4 \\
8.74 \pm 5.56 \\
(3.62-15.14)\end{array}$ & $\begin{array}{c}7 \\
8.46 \pm 4.80 \\
(3.62-15.14)\end{array}$ & $\begin{array}{c}9(15 \%) \\
8.73 \pm 4.20 \\
(3.62-15.14)\end{array}$ \\
\hline All & $\begin{array}{c}8 \\
5.18 \pm 6.93 \\
(-9.04-12.34)\end{array}$ & $\begin{array}{c}8 \\
3.25 \pm 11.96 \\
(-20.81-17.56)\end{array}$ & $\begin{array}{c}16 \\
4.21 \pm 9.49 \\
(-20.81-17.56)\end{array}$ & $\begin{array}{c}22 \\
3.37 \pm 10.21 \\
(-21.33-18.06)\end{array}$ & $\begin{array}{c}22 \\
1.29 \pm 9.89 \\
(-15.75-20.52)\end{array}$ & $\begin{array}{c}44 \\
2.33 \pm 9.99 \\
(-21.33-20.52)\end{array}$ & $\begin{array}{c}60(100 \%) \\
2.83 \pm 9.81 \\
(-21.33-20.52)\end{array}$ \\
\hline
\end{tabular}

Data are shown as mean \pm standard deviation (min-max) or number $(\%)$; -: proximal to zero point

of cases). Therefore, awareness of symmetrical patterns should be emphasized. Location of LB could be found either proximal or distal to the zero point, similar to those found in previous studies $[17,24]$. However, all MTJ of MB was located only proximally to the zero point at a mean distance of $-21.99 \pm$ $\pm 13.21 \mathrm{~mm}$. Low lying lateral MTJ was detected in $66.13 \%$ of the cases and located at a mean distance of $13.10 \pm 4.51 \mathrm{~mm}$ distal to the zero point (Table 2). The prevalence of MTJ type and its location as shown in Table 3 differed from previous studies [17, 24]. The presence of low lying FHL is clinically relevant. It can provide a longer muscle belly for coverage of the injured region and provides adequate vascular supply. However, it can cause FHL tendon entrapment [5]. MTJ can get entrapped at the proximal end of the fibro-osseous tunnel, resulting in limitation of distal excursion of the tendon. This generally causes pain at the entrapment area or the first metatarsophalangeal joint $[9,19]$. This injury is frequently seen in runners, 

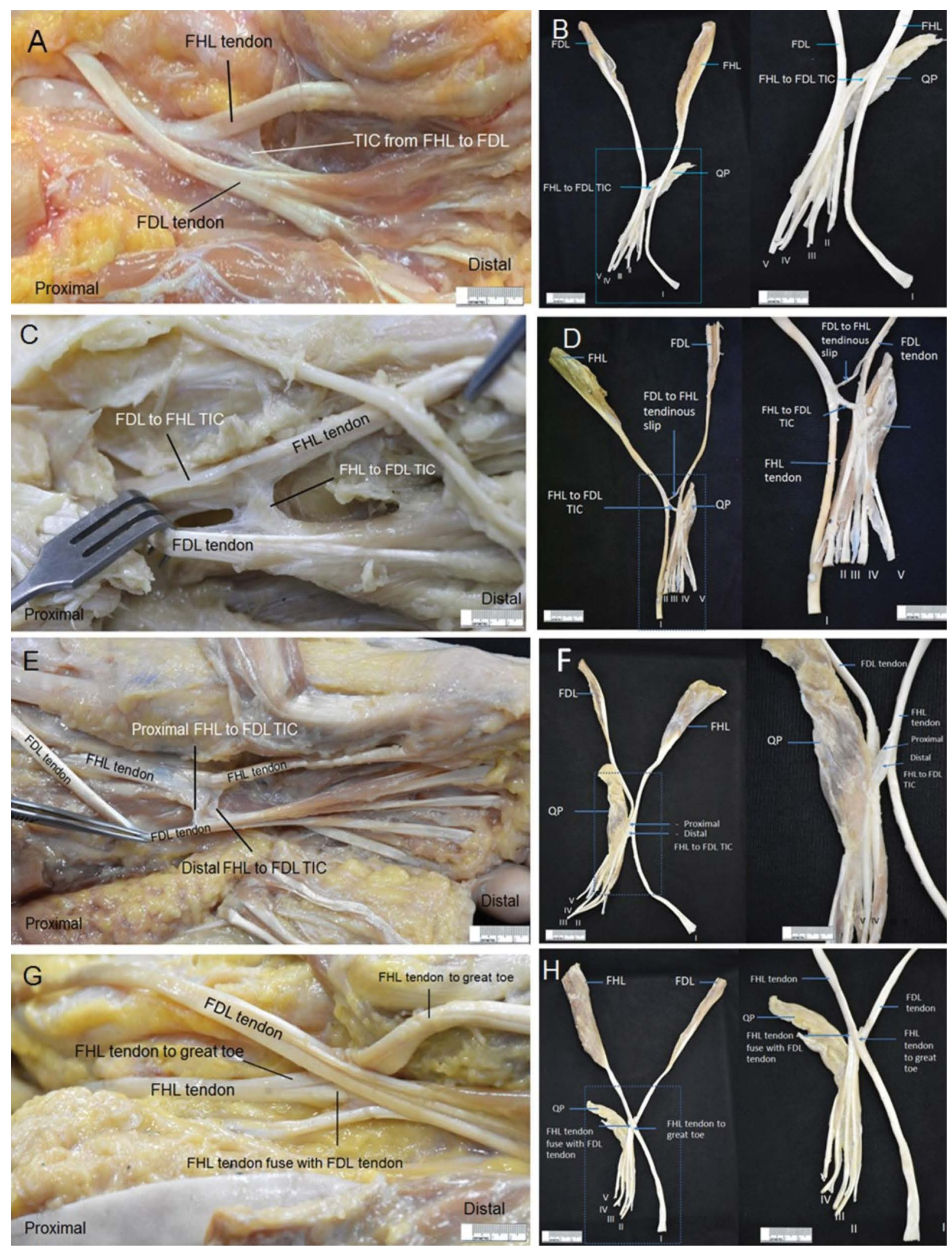

Figure 3. Photographs of left plantar surface of feet and resected flexor hallucis longus (FHL) and flexor digitorum longus (FDL) interconnection showing types of tendinous interconnection (TIC). Type I; FHL to FDL (A, B). Type II; FHL to FDL and FDL to FHL (C, D). Type V; double strands from FHL to FDL (E, F). New type; part of the FHL tendon fused with FDL tendon and the rest extended directly to the great toe $(\mathbf{G}, \mathbf{H})$; MTJ — musculotendinous junction; $\mathrm{QP}$ — quadratus plantae. 
Table 3. Comparisons of musculotendinous junction (MTJ) type and distance from MTJ to measuring point

\begin{tabular}{|c|c|c|c|c|c|c|c|c|}
\hline \multirow[t]{2}{*}{ Author } & \multirow[t]{2}{*}{ Year } & \multirow{2}{*}{$\begin{array}{c}\text { Race/ } \\
\text { /Ethnicity }\end{array}$} & \multirow{2}{*}{$\begin{array}{c}\text { Cadaveric } \\
\text { type }\end{array}$} & \multirow[t]{2}{*}{$\mathbf{N}$} & \multicolumn{4}{|c|}{ MTJ morphology } \\
\hline & & & & & Type 1 & Type 2 & Type 3 & Other \\
\hline This study (2021) & 2020 & Thai & & & & & & \\
\hline \multirow[t]{2}{*}{ Prevalence } & & & Soft & 62 & $145(87.3 \%)$ & $0(0 \%)$ & $21(12.7 \%)$ & $0(0 \%)$ \\
\hline & & & Embalmed & 104 & & & & \\
\hline $\begin{array}{l}\text { Distance from MTJ to the crossing of distal } \\
\text { osseous part of tibia and FHL tendon: }\end{array}$ & & & Soft & 62 & & & & \\
\hline Medial belly [mm] & & & & & \multicolumn{4}{|c|}{$-21.99 \pm 13.21(-65.95--4.93)$} \\
\hline Lateral belly [mm] & & & & & \multicolumn{4}{|c|}{$5.83 \pm 11.64(-30.62-+21.21)$} \\
\hline Mao et al. (2018) [17] & 2018 & Asian & & & & & & \\
\hline Prevalence & & & Embalmed & 70 & $63(90 \%)$ & $5(7.1 \%)$ & $2(2.9 \%)$ & $0(0 \%)$ \\
\hline $\begin{array}{l}\text { Distance from MTJ to the crossing of distal } \\
\text { osseous part of tibia and FHL tendon: }\end{array}$ & & & & 70 & & & & \\
\hline Medial belly $[\mathrm{mm}]$ & & & & & \multicolumn{4}{|c|}{$-33.24 \pm 1.5(-115-+8)$} \\
\hline Lateral belly [mm] & & & & & \multicolumn{4}{|c|}{$-3.14 \pm 2.2(-39-+43)$} \\
\hline Pichler et al. (2005) [24] & 2005 & - & & & & & & \\
\hline Prevalence & & & Embalmed & 80 & $70(88 \%)$ & $3(4 \%)$ & $5(6 \%)$ & $2(3 \%)$ \\
\hline $\begin{array}{l}\text { Distance from MTJ to the bone cartilage } \\
\text { transition of tibia: }\end{array}$ & & & & 80 & & & & \\
\hline Medial belly [mm] & & & & & & $64 \pm 22$. & $(-114-+5$ & \\
\hline Lateral belly [mm] & & & & & & $.48 \pm 12$ & $(-57-+25$ & \\
\hline
\end{tabular}

+ : proximal to measuring point; - : distal to measuring point; $\mathrm{FHL}$ - flexor hallucis longus

tennis players, and dancers, who require dynamic, repetitive, or push-off movement $[19,27]$.

The exact knowledge of TIC anatomy and variation is important for harvesting and estimation of functional loss after transposition [29]. In addition, awareness of the number of connections between FHL and FDL tendons while harvesting tendon grafts distal to $\mathrm{MKH}$ is essential [3]. Results have shown the existence of connection between FHL and FDL tendons in all specimens. The majority of cases in the present study were type I, which was similar to those in previous reports (Table 4) [7, 15, 16, 18, 20, 22, 25, 29, 32]. Types III, IV, $\mathrm{VI}$ and VII were not identified in the present study. In terms of overall proportions, this finding resembles the results of Edama et al. [7] and Mao et al. [17] in Asian cadavers (Table 4). In other ethnic studies, the prevalence of types III, IV, VI and VII varied from $0 \%$ to $30 \%$. Vasudha et al. [29] reported $2.94 \%$ of cases with some unusual fibres from flexor digitorum accessories. Therefore, ethnic differences might exist.

In the results, a new type of TIC was depicted in 14 (8.5\%) cases. The most common TIC distribution found in this type was type b. In the soft cadaveric specimens, the most prevalent location of the fusion point was distal to the MKH. In addition, all cases of the new type were categorised in type 1 MTJ morphology. Hence, the sample size of this study is greater than that of previous reports (Table 4). Therefore, more variations might be seen. The tendinous slips from FHL propose the stable base for toe-off movements [14]. Thus, types of interconnections play a crucial role in defining the level of functional gain of toe movement in the postoperative period [29]. TIC between FHL and FDL tendons might restrict the harvesting of the FHL tendon distal to $\mathrm{MKH}$ [10]. Therefore, it is important to investigate their locations. Moreover, the length of the graft can be increased by including the tendinous interconnection into the graft [29]. Anatomical landmarks including medial malleolus, navicular tuberosity, interphalangeal joint, MKH and FDL tendon division were used previously to locate the TIC between FHL and FDL tendons $[3,5,25]$. MKH was selected as the reference landmark in this study. The surface location of MKH has been reported in our recent study [31]. Results revealed that most of the TIC was located distal to MKH with a similarity to Beger et al. [3]. They also suggested that the interconnection from FHL to FDL could be cut at an average of $27.1 \mathrm{~mm}$ distal to the $\mathrm{MKH}$. However, the average distance from $\mathrm{MKH}$ in our study was shorter $(11.23 \pm 5.13 \mathrm{~mm}$ in low-lying group and $8.73 \pm$ $\pm 4.20 \mathrm{~mm}$ in non-low-lying group). The difference between studies may be due to the number of specimens, method of cadaveric preservation and ethnicity. 





In this study, type $b$ was the most frequent finding of distribution of tendinous slip to lesser toes which was similar to previous reports as shown in Table 4 $[3,7,14,16,25,32]$. Recently, Hirota et al. [12] introduced a FHL tendon branch test in 4 healthy men by electrical stimulation and electromyography recording of FHL and FDL. Considering the branching type, the FHL was presumed to not only act as the great toe flexor, but also play a significant role in the flexion of second and third toes [7, 16]. Toe flexor muscles are key muscles for foot stability and enhancement of sport performance. Therefore, this anatomical knowledge may lead to the benefit of toe muscle exercise for prevention of foot injuries and the improvement of sport performance [11, 12].

\section{CONCLUSIONS}

A revisit of FHL morphology including type and location of MTJ, TIC morphology, pattern of distribution and its location related to the MKH was performed in 31 soft and 52 embalmed cadavers. Two morphological types of MTJ were identified including type 1 $(87.35 \%)$ and type $3(12.65 \%)$. MTJ was found to reside either proximal (-) or distal (+) to the zero point. Lateral muscle belly extended beyond the zero point (low-lying) in $66.13 \%$ of cases with a mean distance of $13.10 \pm 4.51 \mathrm{~mm}$. All medial muscle bellies ended proximally to the zero point with a mean distance of $-21.99 \pm 13.21 \mathrm{~mm}$. TIC type I, II, V and a new type were depicted. The most common was type I (82.93\%). All types of TIC distribution were found and the most prevalent was type $b$ (distributed to second and third toes) $(67.68 \%)$. The most prevalent TIC location was distal to MKH with a mean distance of $11.23 \pm$ $\pm 5.13 \mathrm{~mm}$ in the low-lying group and $8.73 \pm 4.2 \mathrm{~mm}$ in the non-low-lying group. No statistically significant differences were found for all parameters including gender, side, and group.

\section{Acknowledgements}

The authors would like to express our sincere appreciation to all those who have donated their bodies for medical study and research. Special thanks are extended to the technical staffs of the Department of Anatomy, Faculty of Medicine, Chulalongkorn University for their support in cadaveric care. This manuscript was edited by English editing service, Research Affairs, Faculty of Medicine, Chulalongkorn University.

Conflict of interest: None declared

\section{REFERENCES}

1. Alhaug OK, Berdal G, Husebye EE, et al. Flexor hallucis longus tendon transfer for chronic Achilles tendon rupture. A retrospective study. Foot Ankle Surg. 2019; 25(5): 630-635, doi: 10.1016/j.fas.2018.07.002, indexed in Pubmed: 30321934.

2. Amlang $M$, Rosenow MC, Friedrich $A$, et al. Direct plantar approach to Henry's knot for flexor hallucis longus transfer. Foot Ankle Int. 2012; 33(1): 7-13, doi: 10.3113/ FAl.2012.0007, indexed in Pubmed: 22381230.

3. Beger O, Elvan Ö, Keskinbora M, et al. Anatomy of Master Knot of Henry: a morphometric study on cadavers. Acta Orthop Traumatol Turc. 2018; 52(2): 134-142, doi: 10.1016/j.aott.2018.01.001, indexed in Pubmed: 29366540.

4. Cerrato R, Campbell J. Tenodesis and transfer procedures for peroneal tears and tendinosis. Tech Foot Ankle Surg. 2009; 8(3): 119-125, doi: 10.1097/btf.0b013e3181b361e5.

5. Corte-Real NM, Moreira RM, Guerra-Pinto F. Arthroscopic treatment of tenosynovitis of the flexor hallucis longus tendon. Foot Ankle Int. 2012; 33(12): 1108-1112, doi: 10.3113/FAl.2012.1108, indexed in Pubmed: 23199862.

6. Coull R, Flavin R, Stephens MM. Flexor hallucis longus tendon transfer: evaluation of postoperative morbidity. Foot Ankle Int. 2003; 24(12): 931-934, doi: 10.1177/107110070302401211, indexed in Pubmed: 14733350 .

7. Edama M, Kubo M, Onishi $H$, et al. Anatomical study of toe flexion by flexor hallucis longus. Ann Anat. 2016; 204: 80-85, doi: 10.1016/j.aanat.2015.11.008, indexed in Pubmed: 26704354.

8. Hahn F, Meyer P, Maiwald C, et al. Treatment of chronic achilles tendinopathy and ruptures with flexor hallucis tendon transfer: clinical outcome and MRI findings. Foot Ankle Int. 2008; 29(8): 794-802, doi: 10.3113/ FAI.2008.0794, indexed in Pubmed: 18752777.

9. Hamilton WG. Stenosing tenosynovitis of the flexor hallucis longus tendon and posterior impingement upon the os trigonum in ballet dancers. Foot Ankle. 1982; 3(2): 74-80, doi: 10.1177/107110078200300204, indexed in Pubmed: 7141358.

10. Herbst SA, Miller SD. Transection of the medial plantar nerve and hallux cock-up deformity after flexor hallucis longus tendon transfer for Achilles tendinitis: case report. Foot Ankle Int. 2006; 27(8): 639-641, doi: 10.1177/107110070602700814, indexed in Pubmed: 16919220

11. Hirota K, Watanabe K, Saito $Y$, et al. Flexor hallucis longus tendon branch test: Development and validation of a new method to assess anatomical variation of the tendinous slip. Foot Ankle Surg. 2020; 26(6): 607-613, doi: 10.1016/j. fas.2019.08.003, indexed in Pubmed: 31439503.

12. Hirota K, Watanabe K, Teramoto A, et al. Flexor hallucis longus tendinous slips and the relationship to toe flexor strength. Foot Ankle Surg. 2021; 27(8): 851-854, doi: 10.1016/j.fas.2020.11.002, indexed in Pubmed: 33229214.

13. Hockenbury R, Sammarco G. Medial sliding calcaneal osteotomy with flexor hallucis longus transfer for the treatment of posterior tibial tendon insufficiency. Foot 
and Ankle Clinics. 2001; 6(3): 569-581, doi: 10.1016/ s1083-7515(03)00114-1.

14. Hur MS, Kim JH, Woo JS, et al. An anatomic study of the quadratus plantae in relation to tendinous slips of the flexor hallucis longus for gait analysis. Clin Anat. 2011; 24(6): 768-773, doi: 10.1002/ca.21170, indexed in Pubmed: 21812033.

15. LaRue BG, Anctil EP. Distal anatomical relationship of the flexor hallucis longus and flexor digitorum longus tendons. Foot Ankle Int. 2006; 27(7): 528-532, doi: 10.1177/107110070602700708, indexed in Pubmed: 16842720.

16. Mao H, Shi Z, Wapner KL, et al. Anatomical study for flexor hallucis longus tendon transfer in treatment of Achilles tendinopathy. Surg Radiol Anat. 2015; 37(6): 639-647, doi: 10.1007/s00276-014-1399-y, indexed in Pubmed: 25542244.

17. Mao H, Wang L, Dong W, et al. Anatomical feasibility study of flexor hallucis longus transfer in treatment of Achilles tendon and posteromedial portal of ankle arthroscopy. Surg Radiol Anat. 2018; 40(9): 1031-1038, doi: 10.1007/ s00276-018-2021-5, indexed in Pubmed: 29663091.

18. Martin BF. Observations on the muscles and tendons of the medial aspect of the sole of the foot. J Anat. 1964; 98: 437-453, indexed in Pubmed: 14193201.

19. Michelson J, Dunn L. Tenosynovitis of the flexor hallucis longus: a clinical study of the spectrum of presentation and treatment. Foot Ankle Int. 2005; 26(4): 291-303, doi: 10.1177/107110070502600405, indexed in Pubmed: 15829213.

20. Mulier T, Rummens E, Dereymaeker G. Risk of neurovascular injuries in flexor hallucis longus tendon transfers: an anatomic cadaver study. Foot Ankle Int. 2007; 28(8): 910-915, doi: 10.3113/FAl.2007.0910, indexed in Pubmed: 17697656.

21. Murphy RL, Womack JW, Anderson T. Technique tip: a new technique for harvest of the flexor hallucis longus tendon. Foot Ankle Int. 2010; 31(5): 457-459, doi: 10.3113/ FAl.2010.0457, indexed in Pubmed: 20460076.

22. O'Sullivan E, Carare-Nnadi R, Greenslade J, et al. Clinical significance of variations in the interconnections between flexor digitorum longus and flexor hallucis longus in the region of the knot of Henry. Clin Anat. 2005; 18(2): 121-125, doi: 10.1002/ca.20029, indexed in Pubmed: 15696523.

23. Oddy MJ, Flowers MJ, Davies MB. Flexor digitorum longus tendon exposure for flatfoot reconstruction: a comparison of two methods in a cadaveric model. Foot Ankle Surg. 2010; 16(2): 87-90, doi: 10.1016/j.fas.2009.06.003, indexed in Pubmed: 20483141.
24. Pichler W, Tesch NP, Grechenig W, et al. Anatomical variations of the flexor hallucis longus muscle and the consequences for tendon transfer. A cadaver study. Surg Radiol Anat. 2005; 27(3): 227-231, doi: 10.1007/s00276005-0314-y, indexed in Pubmed: 15789138.

25. Plaass $C$, Abuharbid G, Waizy $H$, et al. Anatomical variations of the flexor hallucis longus and flexor digitorum longus in the chiasma plantare. Foot Ankle Int. 2013; 34(11): 1580-1587, doi: 10.1177/1071100713494780, indexed in Pubmed: 23788233.

26. Rodriguez D, Devos Bevernage B, Maldague $P$, et al. Tarsal tunnel syndrome and flexor hallucis longus tendon hypertrophy. Orthop Traumatol Surg Res. 2010; 96(7): 829-831, doi: 10.1016/j.otsr.2010.03.026, indexed in Pubmed: 20851075.

27. Sharpe BD, Steginsky BD, Suhling $M$, et al. Posterior ankle impingement and flexor hallucis longus pathology. Clin Sports Med. 2020; 39(4): 911-930, doi: 10.1016/j. csm.2020.06.001, indexed in Pubmed: 32892975.

28. Sigvard T, Hansen J. Functional reconstruction of the foot and ankle. Lippincott Williams \& Wilkins, a Wolters Kluwer Business, Philadelphia 2000: 422-429.

29. Vasudha TK, Vani PC, Sankaranarayanan G, et al. Communications between the tendons of flexor hallucis longus and flexor digitorum longus: a cadaveric study. Surg Radiol Anat. 2019; 41(12): 1411-1419, doi: 10.1007/s00276-01902311-x, indexed in Pubmed: 31541272.

30. Vega J, Redó D, Savín G, et al. Anatomical variations of flexor hallucis longus tendon increase safety in hindfoot endoscopy. Knee Surg Sports Traumatol Arthrosc. 2017; 25(6): 1929-1935, doi: 10.1007/s00167-017-4465-2, indexed in Pubmed: 28220191.

31. Wan-Ae-Loh P, Danginthawat P, Huanmanop T, et al. Surface localisation of master knot of Henry, in situ and ex vivo length of flexor hallucis longus tendon: pertinent data for tendon harvesting and transfer. Folia Morphol. 2021; 80(2): 415-424, doi: 10.5603/FM.a2020.0045, indexed in Pubmed: 32301100.

32. Wapner KL, Hecht PJ, Shea JR, et al. Anatomy of second muscular layer of the foot: considerations for tendon selection in transfer for Achilles and posterior tibial tendon reconstruction. Foot Ankle Int. 1994; 15(8): 420-423, doi: 10.1177/107110079401500803, indexed in Pubmed: 7981812.

33. Wulker N, Stephens MM, Cracchiolo A. An atlas of foot and ankle surgery. 2 nd ed. Talor \& Francis, London 2005: 377-386. 